\title{
OMEKA: APLIKASI PENGELOLA ARSIP DIGITAL DALAM BERBAGAI FORMAT
}

\author{
Heri Abi Burachman Hakim ${ }^{l}$
}

\begin{abstract}
Abstrak
Arsip memiliki peran penting dalam pengelolaan organisasi atau lembaga. Arsip menjadi salah satu bahan pertimbangan pimpinan untuk mengambil keputusaan. Sejalan dengan perkembangan yang terjadi, informasi tidak hanya disimpan dalam format tercetak, akan tetapi juga disimpan dalam format digital. Pengelolaan arsip digital merupakan usaha yang dilakukan lembaga arsip untuk menyajikan layanan yang sesuai dengan karateristik masyarakat saat ini. Melalui artikel ini penulis ingin berbagi pengetahuan tentang arsip digital serta cara mengelola arsip digital dengan menggunakan Omeka. Omeka merupakan aplikasi pengelolaan arsip digital berbasis open source. Omeka memberikan peluang pengelolaan arsip digital tanpa harus mengeluarkan anggaran pengadaan perangkat lunak. Omeka memberikan peluang pengelolaan arsip digital yang lebih besar. Dengan membaca artikel ini penulis berharap mampu memberikan deskripsi langkah-langkah dalam membangun pengelolaan arsip digital.
\end{abstract}

Kata Kunci: Omeka, arsip digital, aplikasi pengelola arsip, open source

\section{A. Pendahuluan}

Dalam kehidupan ini, individu maupun organisasi tidak dapat dilepaskan dari arsip. Setiap orang akan menghasilkan arsip dalam menjalankan aktivitas hariannya. Ijazah, Kartu Tanda Penduduk (KTP), dan Surat Izin Mengemudi (SIM) merupakan contoh dari arsip yang dihasilkan dari aktivitas harian seseorang. Kondisi seperti ini juga dialami oleh organisasi. Dalam menjalankan aktivitas hariannya, organisasi juga menghasilkan berbagai macam arsip. Arsip ini berfungsi sebagai memori badan korporasi, membantu pengambilan keputusan manajemen, menunjang litigasi, menjunjang efisiensi penggunaan sumber daya dan sebagai rujukan historis ${ }^{2}$.

Menurut Undang-Undang Nomor 43 Tahun 2009 tentang Kearsipan, arsip adalah rekaman kegiatan atau peristiwa dalam berbagai bentuk dan media sesuai

\footnotetext{
${ }^{1}$ Staf UPT Perpustakaan ISI Yogyakarta

${ }^{2}$ Sulistyo-Basuki. Manajemen Arsip Dinamis: Pengantar Memahami dan Mengelola Informasi dan Dokumen, (Jakarta: Gramedia Pustaka Utama, 2003)
} 
dengan perkembangan teknologi informasi dan komunikasi yang dibuat dan diterima oleh lembaga negara, pemerintahan daerah, lembaga pendidikan, perusahaan, organisasi politik, organisasi $\mathrm{k}$ e m a s y a rakat a n, d a n perseorangan dalam pelaksanaan kehidupan bermasyarakat, berbangsa, dan bernegara. ${ }^{3}$

Dari tahun ketahun, tingkat kesadaran masyarakat terhadap pengelolaan arsip mulai meningkat. Berbagai lembaga mulai mendirikan unit arsip. Ilustrasi nyata dapat dilihat dari maraknya perguruan tinggi membangun unit arsip. Fenomena ini wajar, jika melihat fungsi dari arsip bagi lembaga atau organisasi.

Pengelolaan arsip senantiasa m e n i kuti d i n m i ka perkembangan teknologi yang terjadi di masyarakat. Ketika masyarakat hanya mengenal kertas sebagai media perekam informasi, arsip yang dikelola didominasi oleh arsip tercetak. Saat ini masyarakat akrab dengan produkproduk teknologi informasi dalam mendukung aktivitas hariannya. Intensitas interaksi masyarakat dengan produk-produk teknologi menyebabkan arsip mulai diproduksi dalam format digital. Arsip yang terlahir dalam format digital menyebabkan unit pengelola arsip perlu memikirkan strategi pengelolaan arsip digital.
Pengelolaan arsip digital ini akan memberikan peluang lebih kepada masyarakat yang hidup di era digital dalam mengakses arsip.

Sayangnya tidak semua lembaga arsip mampu mengelola arsip digital yang dimiliki. Pengelola arsip selalu terjebak pada stigma bahwa pemanfaatan teknologi informasi untuk membutuhkan biaya yang besar. Unit arsip harus membeli perangkat keras dan lunak yang membutuhkan investasi besar. Padahal dengan fenomena aplikasi open source, saat ini pengelola arsip tidak perlu memikirkan anggaran aplikasi. Pengelola arsip dapat menggunakan aplikasi open source yang dapat digunakan secara gratis sehingga pengelola arsip cukup mengalokasikan anggaran pembelian aplikasi.

Unt uk memberikan pengetahuan tentang cara menggelola arsip digital dengan memanfaatkan aplikasi open source, maka penulis termotivasi untuk membuat tulisan ini. Melalui tulisan ini penulis ingin berbagi pengetahuan tentang definisi arsip digital, format arsip digital, profil aplikasi arsip digital serta tahapan implementasi pengelolaan arsip digital. Dengan membaca tulisan in i diharapkan mampu memberikan ilustrasi cara mengelola arsip digital.

${ }^{4}$ http://archivemati.ca/2005/11/08/digital-archives/ 


\section{B. Kerangka Teori}

\section{Definisi Arsip Digital}

Arsip dimaknai sebagai rekaman kegiatan atau peristiwa dalam berbagai media. Rekaman tersebut disimpan dalam berbagai media yang terus berubah dari waktu ke waktu. Perubahan media penyimpan arsip dipengaruhi oleh dinamika perkembangan teknologi yang terjadi di masyarakat.

Sampai saat ini, media penyimpan arsip didominasi oleh media cetak seperti kertas. Akan tetapi perkembangan teknologi yang terjadi menyebabkan arsip tidak hanya disimpan dalam media cetak, arsip mulai disimpan dalam media elektronik dan dalam format digital. Penyimpanan arsip dalam format digital inilah yang mendorong munculnya istilah arsip digital.

Arsip digital merupakan simpanan kelembagaan yang menyimpan satu atau lebih objek informasi digital dengan tujuan disimpan dalam waktu yang relatif lama dan dapat mengakses informasi digital tersebut. ${ }^{4}$ Definisi lain menyebutkan bahwa arsip digital merupakan arsip yang menyimpan informasi atau aset dalam format digital. Arsip atau aset digital tersebut disimpan dalam simpanan kelembagaan (repository) lengkap dengan dokumen dan sistem manajemen record dan menyajikan informasi dalam berbagai format. $^{5}$

Jika melihat kedua definisi tersebut, dapat disimpulkan bahwa arsip digital merupakan objek atau informasi digital yang tersimpan dalam sebuah simpinan kelembagaan. Objek atau informasi digital tersebut merupakan rekaman kegiatan atau peristiwa suatu lembaga.

Saat ini pengelolaan arsip digital penting untuk dilakukan. Hal ini tidak terlepas dari faktor intensitas masyarakat dalam memanfaatkan produk-produk teknologi informasi. Kondisi ini menyebabkan maraknya informasi kegiatan lembaga diciptakan dan disimpan dalam format digital. Dengan mengelola arsip digital memungkinkan lembaga pengelola arsip memastikan informasi yang disimpan dalam format digital dapat diakses oleh masyarakat tidak terbatas waktu dan memberikan peluang yang lebih luas untuk mengelola arsip. Pengelolaan arsip digital merupakan bentuk penyesuaian yang dilakukan oleh lembaga kearsipan terhadap dinamika yang terjadi di masyarakat. Penyesuaian ini

\footnotetext{
${ }^{4} \mathrm{http}: / /$ archivemati.ca/2005/11/08/digital-archives/

${ }^{5} \mathrm{http} / / / \mathrm{www}$. technologyevaluation.com/search/for/digital-archive-definition.html
} 
merupakan usaha agar lembaga kearsipan dan produk layanannya dapat diakses oleh masyarakat. Selain itu, pengelolaan arsip digital merupakan back up dari pengelolaan arsip dalam format tercetak.

\section{Format Arsip Digital}

Dilihat dari proses penciptaan, arsip digital dapat dibedakan menjadi dua jenis. Jenis pertama adalah arsip digital yang terlahir sebagai arsip digital atau born digital. Ketika pengguna mengetik laporan pertanggungjawaban kegiatan dengan menggunakan aplikasi pengelolah kata seperti Microsoft Office, file laporan pertanggungjawaban tersebut merupakan arsip yang terlahir sebagai arsip digital. Jenis yang kedua adalah arsip digital yang diperoleh dari kegiatan digitalisasi arsip. Melalui kegiatan digitalisasi masyarakat melakukan konversi dari format tercetak atau elektrik ke dalam format digital.

Arsip digital tersimpan dalam berbagai format file yang dapat dibedakan menjadi:

1. Arsip digital berbasis teks

Arsip digital berbasis teks merupakan arsip digital yang didominasi informasi dalam format teks. Arsip digital yang termasuk dalam format ini antara lain file dalam format $. d o c, . x l s$, .ppt dan.pdf.

2. Arsip digital berbasis gambar

Jenis arsip digital lainnya adalah arsip digital berbasis gambar. Gambar dikategorikan sebagai arsip karena gambar merupakan salah satu media perekam informasi. Gambar merekam informasi dalam format visual. Arsip digital berbasis gambar tersimpan dalam berbagai format seperti .jpg, .bmp, .tif dan .png.

3. Arsip digital berbasis audio

Ragam arsip berikutnya adalah arsip dalam format audio. Format arsip ini melengkapi jenis arsip berbasis teks dan gambar. Arsip berbasis audio merekam arsip dalam format suara, sebagai contoh rekaman suara. Jenis arsip berbasis ini adalah $m p 3$ dan mp4.

4. Arsip digital berbasis audio video

Jenis arsip yang terakhir adalah arsip berbasis audio video. Arsip jenis ini merekam informasi dalam format suara dan gambar. Rekaman video aktivitas kantor atau instansi merupakan jenis arsip digital berbasis audio video. Ragam 
jenis arsip ini antara lain: MPEG, avi, 3pg dan MP4.

Seluruh ragam arsip digital tersebut dapat d i k e 1 ol a d e ng a menggunakan Omeka. Omeka memungkinkan penggunanya mengelola arsip dalam berbagai format. Omeka memungkinkan pengguna mengelola arsip digital berbasis teks, gambar, video, dan audio video. Dengan demikian, seluruh ragam koleksi digital dapat dikelola dengan mengguakan Omeka.

\section{Hasil dan Analisis}

\section{Profil Omeka}

Omeka merupakan aplikasi publikasi dokumen digital berbasis open source. Melihat berbagai fasilitas yang tersedia, Omeka dapat digunakan untuk pengelolaan arsip, publikasi kegiatan pameran, manajemen koleksi digital dan sarana pembelajaran. Dari berbagai fasilitas yang disediakan oleh Omeka dapat diketahui bahwa aplikasi ini dapat digunakan oleh lembaga-lembaga pengelola informasi seperti perpustakaan, unit arsip, galeri, dan museum.

Omeka dikembangkan oleh Center for History and New Media. Aplikasi ini disediakan dalam dua versi yaitu versi instalasi offline yang dapat diunduh di www.omeka.org dan versi intalasi yang dapat dilakukan secara online dengan $\mathrm{mengakses}$ website www.omeka.net. Untuk instalasi secara online, omeka.net menyediakan kapasitas server sebesar $64 \mathrm{MB}$.

Sebagai aplikasi yang dikembangkan dengan konsep open source, Omeka juga dibangun dengan menggunakan berbagai aplikasi open source. Berbagai aplikasi open source yang digunakan untuk membangun Omeka antara lain sistem operasi linux, Apache sebagai webserver, MySQL sebagai aplikasi database dan bahasa pemrograman PHP. Omeka direkomendasikan untuk menggunakan sistem operasi linux, akan tetapi aplikasi ini juga mampu berjalan optimal di sistem o p e r a s i $w i n d o w s$. Pemanfaatkan berbagai aplikasi open source ini memberikan peluang kepada pengguna untuk menggunakan aplikasi ini secara gratis, mengembangkan aplikasi ini lebih lanjut, dan mendistribusikan ulang.

Omeka menyediakan berbagai fasilitas. Dengan memafaatkan fasilitas tersebut diharapkan mampu membantu pengguna dalam melakukan pengelolaan arsip digital. Berbagai fasilitas yang disediakan Omeka untuk mengelola arsip digital antara 
lain:

a. Fasilitas manajemen arsip digital

Fasilitas utama yang disediakan Omeka adalah fasilitas pengelolaan arsip $\mathrm{d}$ i g i t a 1 . D e $\mathrm{ng}$ a $\mathrm{n}$ menggunakan Omeka pengguna dapat mengelola koleksi digital berbasis teks, gambar, audio dan video. Pengguna Omeka dapat mengunggah, memperbaiki metadata, dan menghapus data arsip digital. Dengan usaha ini arsip digital dapat diakses oleh pengguna.

b. Publikasi kegiatan pameran

Fasilitas lain yang disedikan oleh Omeka adalah fasilitas publikasi kegiatan pemeran. Lembaga $\mathrm{k}$ e a r i p a n a p t melaksanakan kegiatan pameran arsip secara online.

c. Membuat halaman web

Fasilitas berikutnya yang disediakan Omeka adalah fasilitas pembuatan halaman web. Fasilitas ini membedakan Omeka dengan aplikasi pengelola arsip lainnya. Fasilitas ini memungkinkan pengguna membuat halaman web yang terintegrasi dengan sistem informasi pengelola arsip digital. Dengan fasilitas ini memungkinkan Omeka juga digunakan sebagai web unit pengelola arsip.

d. Fasilitas migrasi data

Fasilitas lain yang disediakan oleh Omeka adalah fasilitas migrasi data. Dengan memanfaatkan fasilitas ini, pengguna Omeka dapat melakukan migrasi data ke dalam Omeka. Dengan fasilitas ini memungkinkan calon pengguna Omeka yang telah menggunakan aplikasi arsip digital lainnya melakukan migrasi data. Dengan demikian pengelola arsip digital tidak perlu memasukkan satu persatu record arsip ke dalam Omeka.

e. Mendukung konsep web 2.0

Sebagai aplikasi berbasis web, Omeka $\mathrm{d}$ i k e m b a $\mathrm{ng}$ k a $\mathrm{n}$ menggunakan konsep web 2.0. Web 2.0 merupakan konsep pengelolaan web yang menyediakan berbagai fasilitas untuk merangsang partisipasi pengguna. Melalui fasilitas tersebut pengguna web dapat memberikan masukan bagi pengelola web. Beberapa fasilitas web 2.0 yang disediakan Omeka seperti sosial bookmarking, tagging, halaman partisipasi pengguna, geolocation dan $R S S$. Dengan berbagai fasilitas tersebut 
memungkinkan masyarakat memberikan masukan serta memberikan penilaian terhadap informasi yang dipublikasikan melalui web lembaga.

f. Tersedia berbagai tema tampilan

Tampilan atau desain halaman sebuah aplikasi dapat memotivasi masyarakat mengakses aplikasi tersebut. Omeka menyediakan berbagai tampilan aplikasi sehingga memungkinkan pengguna merubahan tema tampilan yang digunakan dengan tampilan aplikasi yang lain. Apabila pengguna Omeka memiliki kompetensi programan dan bahasa $H T M L$,pengguna dapat melakukan modifikasi tema tampilan aplikasi.

g. Tersedia berbagai plug-in yang dapat ditambahkan sehingga meningkatkan performa aplikasi

Ketika melakukan instalasi Omeka, maka aplikasi ini menyediakan berbagai fasilitas standar seperti pengelolaan arsip digital, manajemen pengguna aplikasi, pengaturan tampilan dan fasilitas pendukung konsep web 2.0. Sebagai upaya peningkatan kinerja aplikasi Omeka menyediakan berbagai plug-in aplikasi. $\mathrm{D}$ e $\mathrm{ng}$ a $\mathrm{n} p l u g-i n$ memungkinkan omeka meningkatkan kinerja aplikasi.

\section{K e but u h a n d a I a m Implementasi}

Untuk dapat menggunakan Omeka, pengguna perlu melakukan instalasi aplikasi ini. Sebelum melakukan instalasi Omeka, pengguna Omeka perlu menyiapkan beberapa kebutuhan yang meliputi perangkat keras, aplikasi, dan sumber daya manusia. Berikut ini penjelasan dari setiap kebutuhan tersebut:

a. Kebutuhan perangkat keras

Perangkat keras yang perlu disiapkan ketika akan melakukan instalasi Omeka antara lain komputer dan jaringan komputer. Komputer yang dibutuhkan dibedakan menjadi komputer server dan komputer client. Komputer server merupakan komputer yang akan digunakan untuk instalasi Omeka dan komputer client merupakan komputer yang digunakan untuk mengakses dan melakukan operasional Omeka. Kebutuhan selanjutnya adalah jaringan komputer, kebutuhan ini diperlukan agar komputer server dan client dapat 
berkomunikasi. Untuk membangun jaringan komputer ini dibutuhkan switch hub, kabel UTP dan konektor RJ 45.

b. Kebutuhan aplikasi

Kebutuhan aplikasi yang perlu disiapkan, ketika akan melakukan instalasi Omeka antara lain sistem operasi, Apache, PHP dan $M y S Q L$. O m e ka merekomendasikan Linux sebagai sistem operasi, akan tetapi aplikasi ini juga mampu berjalan optimal dengan menggunakan sistem operasi Windows. Omeka juga membutuhkan Apache PHP sebagai bahasa pemrograman dan $M y S Q L$ sebagai aplikasi pengelolaan data.

c. Sumber daya manusia

Sumber daya manusia yang dibutuhkan agar mampu melakukan instalasi dan operasional Omeka dapat dibedakan menjadi administrator Omeka dan operator. Administrator Omeka merupakan SDM yang bertanggung jawab terhadap instalasi dan perawatan Omeka. Administrator Omeka dituntut untuk memiliki kompetensi di bidang teknologi informasi (Sistem operasi, aplikasi berbasis web, database dan jaringan komputer). Sedangkan operator bertanggung jawab terhadap operasional Omeka. Operator membutuhkan kompetensi di bidang ilmu kearsipan.

\section{Tahapan Implementasi}

Setelah mempersiapkan berbagai kebutuhan tersebut, maka pengguna Omeka dapat memulai mengelola arsip dalam format digital Untuk mulai mengelola arsip digital ada beberapa tahapan yang perlu dilalui. Berikut ini adalah berbagai tahapan yang harus dilalui:

a. Desain repository pengelola arsip digital

Dalam mengelola arsip digital diperlukan sebuah repository yang akan digunakan sebagai tempat untuk menyimpan arsip digital. Melalui repository ini masyarakat mengakses arsip digital yang dikelola oleh sebuah lembaga pengelolaan arsip. Dalam membangun sebuah repository pengguna Omeka perlu mendesain bagaimana konsep repository akan dikembangkan. Pengguna perlu menentukan jenis koleksi arsip serta berbagai halaman web yang akan ditampilkan karena Omeka memungkinkan pengguna membangun repository 
pengelolaan arsip sekaligus web perpustakaan.

b. Unduh master aplikasi Omeka

Calon pengguna Omeka perlu menyiapkan master aplikasi ketika akan melakukan instalasi. Pengguna Omeka dapat memperoleh master aplikasi ini dengan mengunduh melalui website resmi Omeka di www.omeka.net.

c. Instalasi Apache, PHP dan MySQL

Pengguna Omeka perlu menyiapkan server yang akan digunakan untuk melakukan instalasi. Selanjutnya pengguna Omeka perlu melakukan instalasi Apache, PHP dan $M y S Q L$ dan setelah itu melakukan instalasi Omeka.

d. Instalasi Omeka

Tahapan implementasi berikutnya adalah melakukan instalasi. Setelah melakukan instalasi Apache, PHP dan MySQL maka penggunaka Omeka atau lembaga arsip dapat melakukan instalasi. Instalasi dilakukan dengan mengikuti panduan instalasi yang disediakan pada web site www.omeka.net.

e. Membuat koleksi

Dalam aplikasi Omeka koleksi dapat dimaknai sebagai kategori atau menunjukkan kepemilikan terhadap sebuah koleksi. Pengguna terlebih dahulu membuat ragam koleksi dengan cara menekan menu koleksi. Setelah itu pengguna dapat mulai mengunggah item atau koleksi digital.

f. Unggah Item

Langkah terakhir dalam tahapan implementasi Omeka sebagai aplikasi pengelola arsip digital adalah unggah item. Item dapat dimaknai sebagai arsip digital yang akan diunggah. Setelah melakukan unggah item maka masyarakat dapat mengakses arsip digital yang dikelola oleh lembaga pengelola arsip.

\section{Aplikasi Pengelola Arsip Digital}

Eksistensi aplikasi open source memberikan harapan bagi mereka yang bekerja di bidang manajemen dokumen atau arsip. Banyak tersedia aplikasi pengelolaan arsip digital yang dapat digunakan tanpa perlu memikirkan anggaran pengadaaan aplikasi. Aplikasi open source juga memungkinkan pengguna aplikasi ini mengembangkan dan mendistribusikan ulang aplikasi.

Setiap aplikasi arsip digital memiliki keunggulan dan 
kelemahan. B erbagai keunggulan yang dapat dijadikan sebagai pertimbangan dalam memiliki Omeka sebagai aplikasi pengelola arsip digital antara lain:

a. Omeka menyediakan berbagai fasilitas untuk melakukan pengelola arsip digital

Telah dijelaskan di awal bahwa arsip digital akan disimpan dalam sebuah repository atau simpanan kelembagaan. Menurut B a y ley $\mathrm{simpanan}$ kelembagaan merupakan sistem elektronik untuk menghimpun, mengemas ulang dan melakukan preservasi terhadap hasil intelektual yang dihasilkan kerja sama berbagai perguruan tinggi atau sebuah perguruan tinggi. ${ }^{6}$ Dari definisi tersebut dapat diketahui bahwa aplikasi pengelola arsip digital harus mampu menjadi sistem elektronik yang digunakan un tuk menyimpan, mengemas, serta melakukan preservasi terhadap arsip digital. Omeka menyediakan fasilitas untuk menyimpan dan melakukan preservasi. Omeka juga menyediakan fasilitas penelusuran yang memungkinkan pengguna menelusur arsip yang dibutuhkan. Selain itu pengguna juga dapat mengakses arsip digital yang dikelola dengan Omeka secara full text.

b. Omeka mampu mengelola berbagai format arsip digital

O meka m a m p u mengelola seluruh ragam arsip digital dalam format teks, gambar, audio dan video. Setelah diunggah ke dalam Omeka, arsip digital tersebut dapat diakses oleh masyarakat. Omeka juga menyediakan fasilitas streaming untuk arsip audio dan video sehingga lebih memberikan kenyamanan bagi pengguna dalam mengakses arsip audio dan video.

c. Omeka dikembangkan dengan konsep open source

Omeka dikembangkan dengan berbagai komponen open source seperti bahasa pemrograman $P H P$, database MySQL, Apache sebagai web server dan sistem operasi Linux. Dengan menggunakan beberapa komponen tersebut memungkinkan pengguna mengembangkan lebih lanjut Omeka karena source code aplikasi ini terbuka. Konsep open source yang

\footnotetext{
${ }^{6}$ Katayoon Kamraninia and A. Abrizah. Librarians' role as change agents for institutional repositories: A case of Malaysian academic libraries (Malaysian Journal of Library \& Information Science, Vol. 15, no.3, Dec 2010), hal 2
} 
d i g u nakan d a 1 a m pengembangan Omeka, memberikan peluang pengguna menggunakan aplikasi ini secara gratis serta mendistribusikan ulang Omeka.

d. Omeka didesain untuk pengguna yang tidak memiliki kompetesi yang tinggi di bidang teknologi informasi.

Aplikasi ini didesain untuk arsiparis yang tidak memiliki kompetesi bidang teknologi informasi. Arsiparis dapat melakukan instalasi untuk mengelola arsip digital secara mandiri dan tidak bergantung kepada praktisi di bidang teknologi informasi.

e. $O m e k a \quad \mathrm{~m} \mathrm{e} \mathrm{m} \mathrm{i} 1 \mathrm{ik} \mathrm{i}$ $\mathrm{k}$ e $\mathrm{m}$ a $\mathrm{m}$ p $\mathrm{u}$ a $\mathrm{n}$ interoperabilitas

Interoperabilitas merupakan kemampuan perangkat lunak untuk melakukan pertukaran data dengan perangkat lunak lain. Un t u k melak ukan pertukaran data ini, perangkat lunak harus menggunakan protokol yang sama. Omeka dikembangkan dengan menggunakan protokol OAI-PMH Repository. Perangkat lunak yang menggunakan protokol yang sama dengan Omeka memungkinkan melakukan pertukaran data dengan perangkat lunak ini.

Omeka memberikan harapan bagi pengelola arsip di tanah air untuk mampu mengelola arsip digital yang dimiliki. Omeka sebagai perangkat lunak open souce memberikan peluang untuk mengelola arsip digital dengan investasi sumber daya yang lebih kecil. Dengan melakukan investasi perangkat keras maka implementasi pengelolaan arsip digital berbasis Omeka dapat segara dilakukan.

\section{Penutup}

\section{Kesimpulan}

Dari pemaparan tersebut, ada beberapa kesimpulan yang diperoleh antara lain:

a. Saat ini arsip digital mudah $\mathrm{d}$ i c i p t a k a n d a n perkembangan teknologi informasi mengubah pola akses masyarakat dalam mengakses informasi. Kondisi ini perlu direspon oleh lembaga kearsipan untuk mengelola arsip digital. Upaya ini merupakan u saha penyusuaian lembaga kearsipan untuk menjadi lembaga yang sesuai dengan harapan masyarakat pengguna.

b. Omeka dapat menjadi salah satu alternatif aplikasi 
pengelolaan arsip digital. Selama ini pengelola arsip digital sulit dilakukan karena harga aplikasi yang mahal serta minimnya sumber daya manusia yang miliki kompetensi di bidang teknologi informasi. Dengan melakukan investasi perangkat keras, pengelolaan arsip digital dapat dilakukan. Instalasi dan operasional Omeka yang didesain sederhana $\mathrm{m}$ e $\mathrm{m} \mathrm{u} \mathrm{ng} \mathrm{k} \mathrm{i} \mathrm{k} \mathrm{a} \mathrm{n}$ implementasi pengelolaan arsip digital oleh arsiparis.

c. Omeka mampu mengelola arsip digital dalam format teks, gambar, audio dan video sehingga layanan direkomendasikan sebagai aplikasi pengelola arsip digital

d. Omeka merupakan aplikasi berbasis web yang memberikan peluang masyarakat mengakses arsip digital tanpa harus datang ke unit arsip. Dengan demikian, masyarakat yang tidak memiliki waktu luang dapat mengakses arsip tanpa perlu datang langsung ke unit asip.

e. $O m e k a \quad \mathrm{~m}$ e mil i k i $\mathrm{k}$ e $\mathrm{m}$ a $\mathrm{m}$ p u a $\mathrm{n}$ interoperabilitas yang dapat dijadikan sebaga i pertimbangan untuk memilih aplikasi ini sebagai aplikasi pengelola arsip digital. Protokol OAI-PMH
Repository yang digunakan Omeka, memungkinkan aplikasi ini bertukar data dengan aplikasi pengguna protokol yang sama.

\section{Saran}

Berdasarkan analisis dan hasil kesimpulan yang diperoleh, ada beberapa saran yang direkomendasikan antara lain:

a. Peluang pengelolaan arsip digital perlu direspon oleh arsiparis. Respon yang diberikan arsiparis adalah usaha untuk belajar tentang cara melakukan instalasi dan menjalankan program Omeka.

b. Pimpinan lembaga tempat lembaga kearsipan berdiri perlu m e nd u k u g implementasi pemanfaatan Omeka sebagai aplikasi pengelola kearsipan. Dukungan yang diberikan tersebut adalah kebijakan y a n g m e d u k u n g implementasi pengelolaan arsip digital.

\section{DAFTAR PUSTAKA}

Center For History and New Media. "Omeka: An Open-Source, Free Toolkit for Exhibiting Collections Online”. Diakses melalui www.Omeka.org pada tanggal 6 April 2015 Pukul 15.14 WIB 
Digital archives Definition, diakses melalui http://archivemati.ca/ 2005/11/08/digital-archives/ Pada tanggal 28 Juli 201515.00 WIB

Digital Archive Definition, diakses m e 1 a $1 \mathrm{u} \mathrm{i}$ h t t p : / / www.technologyevaluation.com /search/for/digital-archivedefinition.htmlPada tanggal 28 Juli 2015 15.00 WIB

Feather, John and Sturges, Paul. 2003. International Encyclopedia of Information and Library Science. London: Routledge.

Undang-Undang Nomor 43 Tahun 2009 tentang Kearsipan.

Kamraninia, Katayoon and Abrizah, A. Librarians' role as change agents for institutional repositories: A case of Malaysian academic libraries dalam Malaysian Journal of Library \&
Information Science, Vol. 15, No.3, December 2010

Sulistyo-Basuki. 2003. Manajemen Arsip Dinamis: Pengantar Memahami dan Mengelola Informasi dan Dokumen. Jakarta: Gramedia Pustaka Utama. 